Ribeiro, WA, Felipe, BSB \& Oliveira, RVG (2020). The role of nurses in palliative care for cancer patients: a study of Brazilian reviews. Research, Society and Development, 9(7):1-21, e234973905.

\title{
Protagonização do enfermeiro nos cuidados paliativos do paciente oncológico: um estudo das revisões brasileiras
}

The role of nurses in palliative care for cancer patients: a study of Brazilian reviews

El papel de las enfermeras en los cuidados paliativos para pacientes con cáncer: un estudio de revisiones brasileñas

Recebido: 23/04/2020 | Revisado: 25/04/2020 | Aceito: 30/04/2020 | Publicado: 09/05/2020

Wanderson Alves Ribeiro

ORCID: https://orcid.org/0000-0001-8655-3789

Universidade Iguaçu/Universidade Castelo Branco, Brasil

E-mail: nursing_war@ hotmail.com

Bruna dos Santos Bulhões Felipe

ORCID: https://orcid.org/0000-0003-2647-7547

Universidade Castelo Branco, Brasil

E-mail: bruna-msb@hotmail.com

Raísa Vitória Guedes de Oliveira

ORCID: https://orcid.org/0000-0002-9789-9563

Universidade Castelo Branco, Brasil

E-mail: raissa.oliver@yahoo.com.br

\section{Resumo}

Câncer é o nome geral dado a um conjunto de mais de 100 doenças, que têm em comum no crescimento desordenado de células, que tendem a invadir tecidos e órgãos vizinhos. Esta patologia se destaca pelas suas altas taxas de incidência e mortalidade. Estima-se que no mundo em 2020, ocorrerá aproximadamente 15 milhões de novos casos. Tem-se como objetivos compreender a protagonização do enfermeiro na assistência ao paciente oncológico paliativo. Analisar protagonização do enfermeiro frente a SAE no cuidado a pacientes oncológicos paliativos apontadas nas produções científicas. Trata-se de um estudo de revisão bibliográfica, de cunho descritivo e de abordagem qualitativa. Foram realizadas buscas na base de dados da Biblioteca Virtual em Saúde (BVS), entre junho e novembro de 2019. Foram analisados quatro artigos, resultando na formação de duas categorias: Ações de 
cuidado a pacientes oncológicos e fatores influenciadores para a prática do cuidado. A equipe de enfermagem é de suma importância ao paciente em cuidados paliativos e, também serve de apoio para a família, dando todo suporte necessário e segurança ao paciente em fase terminal, contribuindo para o conforto do paciente. A utilização do diagnóstico de enfermagem, traz benefícios tanto para o paciente quanto para o desempenho das atividades de enfermagem em si, pois orientam através do processo de enfermagem, quanto as necessidades individuais de cada paciente. Conclui-se que a enfermagem é de suma importância na assistência ao paciente terminal oncológico. A SAE é o instrumento utilizado para sistematizar a assistência de enfermagem, e o enfermeiro é o principal responsável por sua aplicabilidade.

Palavras-chave: Cuidados paliativos; Enfermeiros; Oncologia; Processos de Enfermagem; Equipe de enfermagem.

\section{Abstract}

Cancer is the general name given to a set of more than 100 diseases, which have in common in the disordered growth of cells, which tend to invade neighboring tissues and organs. This pathology stands out for its high incidence and mortality rates. It is estimated that in the world in 2020, there will be approximately 15 million new cases. Its objectives are to understand the role of nurses in assisting palliative cancer patients. To analyze the role of nurses in front of $\mathrm{SAE}$ in the care of palliative cancer patients pointed out in scientific productions. This is a study of bibliographic review, of a descriptive nature and with a qualitative approach. Searches were carried out in the database of the Virtual Health Library (VHL), between June and November 2019. Four articles were analyzed, resulting in the formation of two categories: Care actions for cancer patients and influencing factors for the practice of care. The nursing team is of paramount importance to the patient in palliative care and also serves as support for the family, giving all necessary support and safety to the terminally ill patient, contributing to the patient's comfort. The use of the nursing diagnosis brings benefits both to the patient and to the performance of the nursing activities themselves, as they guide through the nursing process, as to the individual needs of each patient. It is concluded that nursing is of paramount importance in assisting terminal cancer patients. SAE is the instrument used to systematize nursing care, and the nurse is primarily responsible for its applicability.

Keywords: Palliative care; Nurses; Oncology; Nursing processes; Personal nursing. 


\section{Resumen}

Cáncer es el nombre general dado a un conjunto de más de 100 enfermedades, que tienen en común el crecimiento desordenado de las células, que tienden a invadir los tejidos y órganos vecinos. Esta patología destaca por sus altas tasas de incidencia y mortalidad. Se estima que en el mundo en 2020, habrá aproximadamente 15 millones de casos nuevos. Sus objetivos son comprender el papel de las enfermeras en la asistencia a pacientes con cáncer paliativo. Analizar el papel de las enfermeras frente a SAE en el cuidado de pacientes con cáncer paliativo señalado en producciones científicas. Este es un estudio de revisión bibliográfica, de carácter descriptivo y con enfoque cualitativo. Se realizaron búsquedas en la base de datos de la Biblioteca Virtual en Salud (BVS), entre junio y noviembre de 2019. Se analizaron cuatro artículos, lo que resultó en la formación de dos categorías: acciones de atención para pacientes con cáncer y factores influyentes para la práctica de la atención. El equipo de enfermería es de suma importancia para el paciente en cuidados paliativos y también sirve como apoyo para la familia, brindando todo el apoyo y la seguridad necesarios al paciente terminal, contribuyendo a la comodidad del paciente. El uso del diagnóstico de enfermería brinda beneficios tanto para el paciente como para el desempeño de las actividades de enfermería en sí mismas, ya que guían a través del proceso de enfermería y las necesidades individuales de cada paciente. Se concluye que la enfermería es de suma importancia para ayudar a los pacientes con cáncer terminal. SAE es el instrumento utilizado para sistematizar la atención de enfermería, y la enfermera es la principal responsable de su aplicabilidad.

Palabras clave: Cuidados paliativos; Enfermeras; Oncología; Procesos de enfermería;

Personal de enfermería.

\section{Introdução}

O câncer é definido como, um abrangente grupo de doenças que pode afetar qualquer parte do organismo. Tem como característica o crescimento desordenado de células que sofreram mutação, podendo afetar outros tecidos, tornando-se um problema de saúde pública mundial. Segundo a Organização Mundial de Saúde, estima-se a ocorrência de 15 milhões de novos casos de câncer no mundo em 2020. E no Brasil, estimou-se mais de 420 mil novos casos de câncer para os anos de 2016 e 2017, sem contar os de pele não melanoma (cerca de 180 mil) (Braz et. al., 2018).

Segundo o INCA (2017), as doenças e agravos não transmissíveis, se tornaram as principais responsáveis pelo adoecimento e óbito da população no mundo. Em 2008, estima- 
se que 36 milhões dos óbitos, ocorreram em consequência das doenças e agravos não transmissíveis, tendo como destaque as doenças cardiovasculares e o câncer. No Brasil, em 2018 e 2019, estima-se em cada ano, 600 mil novos casos de câncer.

Cabe ressaltar que o câncer é o nome dado a um conjunto de mais de 100 doenças que têm em comum o crescimento desordenado, chamado de câncer maligno, de células que invadem os tecidos e órgãos, podendo espalhar-se para outras regiões do corpo, sendo chamado de metástase. Dividindo-se rapidamente, estas células tendem a ser muito agressivas e incontroláveis, ocorrendo o acúmulo de células cancerosas, sendo chamado de tumor ou neoplasias malignas. Um tumor benigno significa uma massa localizada de células que se multiplicam vagarosamente e se assemelham ao seu tecido original, raramente constituindo um risco de vida (Brasil, 2015).

Os diferentes tipos de câncer correspondem aos vários tipos de células do corpo. Temos como exemplo, o câncer de pele, pois a pele é formada por mais de um tipo de célula. Se o câncer tem início em tecidos epiteliais como a pele ou mucosas ele é denominado carcinoma. Se começa em tecidos conjuntivos como osso, músculo sou cartilagem é chamado de carcinoma. Outras características que diferenciam os diversos tipos de câncer são a velocidade de multiplicação das células e a capacidade de invadir tecidos e órgãos vizinhos ou distantes chamado de metástase (Brasil, 2014).

As células que constituem os animais são formadas por três partes: a membrana celular, que é a parte mais externa; o citoplasma que é o corpo da célula; e o núcleo, que contêm os cromossomas, que são compostos de genes. Os genes são arquivos que guardam e fornecem instruções para a organização das estruturas, formas e atividades das células no organismo. Toda a informação genética encontra-se nos genes, conhecido como DNA. É através do DNA que os cromossomos passam as informações para o funcionamento da célula (Brasil, 2015).

As causas de câncer são variadas, podendo ser externas ou internas ao organismo, estando ambas relacionadas. As causas externas estão associadas ao meio ambiente e aos hábitos ou costumes próprios de um ambiente social e cultural. As causas internas são, na maioria das vezes, geneticamente pré-determinadas, estão relacionadas à capacidade do organismo de se defender das agressões externas. Esses fatores podem relacionar-se de várias formas, aumentando a probabilidade de transformações malignas nas células normais (Brasil, 2014).

Segundo o INCA, $80 \%$ a 90\% dos cânceres estão associados a fatores ambientais. Como o cigarro pode causar câncer de pulmão, a exposição excessiva ao sol pode causar 
câncer de pele, e alguns vírus podem causar leucemia. Outros ainda estão em estudo, como alguns componentes dos alimentos que ingerimos, e outros são ainda completamente desconhecidos (Brasil,2015).

Para o INCA (2018), o principal objetivo da prevenção do câncer se dá em impedir que ele se desenvolva, com hábitos saudáveis e evitando se expor a substancias cancerígenas. A segunda forma de prevenção é tratar doenças que podem se tornar malignas. Dentre os fatores de riscos estão: tabagismo, alcoolismo, obesidade, doenças cardiovasculares e respiratórias e exposição solar.

O envelhecimento traz mudanças nas células que aumentam a sua suscetibilidade à transformação maligna. Somando o fato de as células das pessoas idosas terem sido expostas por mais tempo aos diferentes fatores de risco para câncer, isso explica em parte o motivo de existir mais casos de câncer nesses indivíduos. Os fatores de risco ambientais de câncer são denominados cancerígenos ou carcinógenos. Esses fatores atuam alterando a estrutura genética (DNA) das células (Brasil, 2012).

O surgimento do câncer depende da intensidade e duração da exposição das células aos agentes causadores de câncer. Por exemplo, o risco de uma pessoa desenvolver câncer de pulmão é diretamente proporcional ao número de cigarros fumados por dia e ao número de anos que ela vem fumando (Brasil, 2012).

Os fatores de risco de câncer podem ser encontrados no meio ambiente ou podem ser herdados. A maioria dos casos de câncer está ligada ao meio ambiente, onde encontramos um grande número de fatores de risco. Entende-se por ambiente a água, terra e ar, o ambiente ocupacional a indústrias químicas e afins, o ambiente de consumo os alimentos e medicamentos, o ambiente social e cultural, estilo e hábitos de vida. As mudanças provocadas no meio ambiente pelo próprio homem, os hábitos adotados pelas pessoas, podem determinar diferentes tipos de câncer como: tabagismo, hábitos alimentares, alcoolismo, hábitos sexuais, medicamentos, fatores ocupacionais e radiação solar (Brasil, 2002).

Alguns tipos de câncer de mama, estômago e intestino parecem ter um forte componente familiar, embora não se possa afastar a hipótese de exposição dos membros da família a uma causa comum. Determinados grupos étnicos parecem estar protegidos de certos tipos de câncer a exemplo disso está à leucemia linfocítica que é rara em orientais, e o sarcoma de Ewing que é muito raro em negros (Brasil, 2014).

O câncer, por ser uma doença com aspectos clínico-patológicos e várias localizações e não possuir sinais ou sintomas específicos pode ser detectado em vários estágios de evolução clínica e histológica, tendo o diagnóstico, principalmente o diagnóstico precoce, um ponto de 
fundamental importância para o tratamento e resposta efetiva ao tratamento (OLIVEIRA, 2015).

A equipe de enfermagem desempenha papel importantíssimo no cuidado ao paciente oncológico. Diante disso, o enfermeiro precisa estar preparado para cuidar desse paciente assistindo - o como um todo, dirimindo o sofrimento de conviver com a doença assim como os efeitos do tratamento (Salimena et. al., 2013).

No que se refere ao cuidado, especialmente ao paciente com uma doença em estágio avançado e um prognostico ruim, torna-se direcionado para suas necessidades limitações, pois a morte é irreversível e o tempo de vida torna-se restrito há dias semanas ou meses. Com isso, torna de suma importância um plano de cuidados que aborde o bom estarem do paciente em todas as suas necessidades, com a finalidade de proporcioná-lo uma melhor qualidade de vida assim como minimizar o sofrimento e a dor. A assistência aos pacientes sob cuidados paliativos é de suma importância, visto que exige do enfermeiro e da equipe de enfermagem em geral, um olhar atento e cauteloso. Com uma visão holística os cuidados paliativos têm como finalidade, valorizar a vida e encarar a morte como um processo natural, sem a intenção de adiar ou prolongar a morte, e sim amparando suas angustias, promovendo o alivio da dor e outros sintomas, dando ao paciente a possibilidade de viver de forma mais ativa possível (Fernandes et. al., 2013).

A motivação para pesquisá-la surgiu com a vivência profissional em um setor de oncologia de um hospital privado na zona norte do Rio de Janeiro, onde foi possível observar a importância e a responsabilidade do enfermeiro frente aos cuidados aos pacientes oncológicos em tratamento paliativo, assim como a peculiaridade desse tipo de paciente e a importância que a assistência do enfermeiro faz no cuidado ao paciente oncológico terminal assistindo de maneira holística e dando devida importância ao tratamento do paciente.

Diante do exposto, o artigo emergiu as seguintes questões norteadora: Qual a protagonização do enfermeiro na assistência ao paciente oncológico paliativo? E Qual a ótica do enfermeiro frente a SAE na assistência ao paciente oncológico paliativo?

Para atender as demandas da pesquisa, tem-se como objetivo geral: compreender a protagonização do enfermeiro na assistência ao paciente oncológico paliativo e, como objetivos específicos: descrever a protagonização do enfermeiro na assistência ao paciente oncológico paliativo e discutir a percepção do enfermeiro frente a SAE na assistência ao paciente oncológico paliativo. 


\section{Metodologia}

Segundo Lakatos \& Marcone (2003), conhecimento científico determina a utilização de métodos científicos; por outro lado, não são todos os estudos que utilizam esse modelo é reconhecido como ciência.

Perante a certificação, pode-se deduzir que a aplicação de métodos científicos não é competência especifica da ciência, com tudo não existe ciência sem o uso de métodos científicos. Como tal característica, o método é a agregação de atividades sistemáticas e lógicas que, permite com total segurança e economia, atingir o objetivo, com estudos validos e verdadeiros, elaborando roteiros a seres seguidos, encontrando erros e contribuindo com soluções dos cientistas (Lakatos \& Marcone, 2003).

$\mathrm{Na}$ atualidade têm-se uma farta e complexa quantidade de dados na área da saúde, fazendo assim, com que haja necessidade de desenvolvimento de artigos e pesquisas, com embasamento cientifico, para possibilitar melhor delimitação metodológica esclarecendo diversos estudos. Mediante a necessidade, utilizamos a revisão bibliográfica como uma forma de metodologia que possibilita um apanhado de conhecimentos e aplica-se em resultados de estudos concisos na pratico do profissional (Souza et. al. 2010).

Trata-se de um estudo de revisão bibliográfica, de caráter descritivo e de abordagem qualitativa. A pesquisa científica é a atuação básica das ciências na sua indagação e construção da realidade, tornando-a uma atividade expressiva (Minayo, 2013).

Abordagem qualitativa é aquela que não trabalha com informações numéricas, mas sim, que trabalha com conceitos, ideologias, processos de comunicação humana, entre outros. E apresenta facilidade de definir hipótese ou problema, de explorar a interação de certas variáveis, de compreender e classificar processos dinâmicos experimentados por grupos sociais, de apresentar mudanças, elaboração ou formação de posição de determinados grupos, e de permitir, em grau de profundidade, a interpretação dos comportamentos ou atitudes dos indivíduos (Gil, 2008).

Foram realizadas buscas na base de dados da Biblioteca Virtual em Saúde (BVS) Bireme, entre junho e novembro, 2019, nas bases de dados: Literatura Latico Americana e do Caribe em Ciência da Saúde (LILACS), Bases de Dados da Enfermagem (BDENF), Biblioteca Eletrônica Cientifica Online (SciELO).

Para a busca das referências foram utilizados os descritores "cuidados paliativos", "enfermeiros", “oncologia", "processos de enfermagem", “equipe de enfermagem", advindos do sistema de Descritores em ciências da saúde (DeCS), utilizando o marcador “ $A N D$ ”. Para 
Research, Society and Development, v. 9, n. 7, e234973905, 2020

(CC BY 4.0) | ISSN 2525-3409 | DOI: http://dx.doi.org/10.33448/rsd-v9i7.3905

resgaste dos artigos, consideramos como critérios para inclusão artigos publicados no período compreendido entre os anos 2013 e 2018, com textos completos em língua portuguesa. E os critérios de exclusão foram os artigos repetidos, publicações com textos não disponíveis, fora da língua vernácula e estudos com mais de dez anos de publicação.

Inicialmente foram pesquisados os descritores individualmente, sendo encontrados artigos científicos conforme Quadro 1, a seguir:

\section{Quadro 1}

\begin{tabular}{|c|c|c|c|c|}
\hline Palavras-chave & BDENF & LILACS & MEDLINE & Total de artigos \\
\hline Cuidados paliativos & 32 & 58 & 39 & 129 \\
\hline Enfermeiro & 303 & 350 & 161 & 814 \\
\hline Oncologia & 39 & 136 & 48 & 223 \\
\hline $\begin{array}{c}\text { Processo de } \\
\text { enfermagem }\end{array}$ & 348 & 421 & 44 & 613 \\
\hline $\begin{array}{c}\text { Equipe de } \\
\text { enfermagem }\end{array}$ & 256 & 323 & 43 & 622 \\
\hline
\end{tabular}

Diante do extenso número de publicações encontradas, realizou-se um refinamento na busca. Os descritores foram pesquisados de forma associada em dupla, utilizando o termo “and", conforme Quadro 2: 
Research, Society and Development, v. 9, n. 7, e234973905, 2020

(CC BY 4.0) | ISSN 2525-3409 | DOI: http://dx.doi.org/10.33448/rsd-v9i7.3905

Quadro 2 - Distribuição quantitativa das produções científicas encontradas nas bases de dados com descritores associados em dupla.

\begin{tabular}{|c|c|c|c|c|}
\hline \multicolumn{5}{|c|}{ Banco de Dados } \\
\hline Palavras-chave & Lilacs & Bdenf & Medline & Total \\
\hline $\begin{array}{c}\text { Cuidados paliativos AND } \\
\text { enfermeiro }\end{array}$ & 5 & 5 & 2 & 12 \\
\hline $\begin{array}{c}\text { Cuidados paliativos AND } \\
\text { oncologia }\end{array}$ & 11 & 5 & 0 & 16 \\
\hline $\begin{array}{l}\text { Cuidados paliativos AND } \\
\text { processo de enfermagem }\end{array}$ & 11 & 7 & 1 & 19 \\
\hline $\begin{array}{c}\text { Cuidados paliativos AND equipe } \\
\text { de enfermagem }\end{array}$ & 7 & 3 & 1 & 11 \\
\hline Enfermeiro AND oncologia & 11 & 10 & 1 & 22 \\
\hline $\begin{array}{c}\text { Enfermeiro AND processo de } \\
\text { enfermagem }\end{array}$ & 92 & 90 & 14 & 196 \\
\hline $\begin{array}{c}\text { Enfermeiro AND equipe de } \\
\text { enfermagem }\end{array}$ & 65 & 61 & 12 & 138 \\
\hline $\begin{array}{l}\text { Equipe de enfermagem AND } \\
\text { cuidados paliativos }\end{array}$ & 7 & 3 & 0 & 10 \\
\hline $\begin{array}{l}\text { Equipe de enfermagem AND } \\
\text { processo de enfermagem }\end{array}$ & 77 & 75 & 4 & 156 \\
\hline $\begin{array}{c}\text { Equipe de enfermagem AND } \\
\text { oncologia }\end{array}$ & 9 & 6 & 0 & 15 \\
\hline $\begin{array}{c}\text { Oncologia AND processo de } \\
\text { enfermagem }\end{array}$ & 13 & 12 & 0 & 25 \\
\hline
\end{tabular}

Considerando ainda ser extensa a quantidade de produções científicas, optou-se pela busca com os descritores associados em trio. Os resultados dessa busca se encontram descritos no Quadro 3. 
(CC BY 4.0) | ISSN 2525-3409 | DOI: http://dx.doi.org/10.33448/rsd-v9i7.3905

Quadro 3 - Distribuição quantitativa das produções científicas encontradas nas bases de dados com os descritores associados em trio.

\begin{tabular}{|c|c|c|c|c|}
\hline \multicolumn{5}{|c|}{ BANCO DE DADOS } \\
\hline Palavras-chave & Lilacs & Bdenf & Medline & Total \\
\hline $\begin{array}{l}\text { Cuidados paliativos AND } \\
\text { enfermeiro AND oncologia }\end{array}$ & 3 & 3 & 0 & 6 \\
\hline $\begin{array}{l}\text { Cuidados paliativos AND } \\
\text { enfermeiro AND processo de } \\
\text { enfermagem }\end{array}$ & 1 & 1 & 0 & 2 \\
\hline $\begin{array}{c}\text { Cuidados paliativos AND } \\
\text { enfermeiro AND equipe de } \\
\text { enfermagem }\end{array}$ & 1 & 1 & 0 & 2 \\
\hline $\begin{array}{l}\text { Enfermeiro AND oncologia AND } \\
\text { processo de enfermagem }\end{array}$ & 6 & 7 & 0 & 13 \\
\hline $\begin{array}{l}\text { Enfermeiro AND oncologia AND } \\
\text { equipe de enfermagem }\end{array}$ & 2 & 2 & 0 & 4 \\
\hline $\begin{array}{c}\text { Oncologia AND equipe de } \\
\text { enfermagem AND processo de } \\
\text { enfermagem }\end{array}$ & 6 & 4 & 0 & 10 \\
\hline $\begin{array}{c}\text { Processo de enfermagem AND } \\
\text { oncologia AND cuidados } \\
\text { paliativos }\end{array}$ & 2 & 1 & 0 & 3 \\
\hline $\begin{array}{c}\text { Processo de enfermagem AND } \\
\text { enfermeiro AND equipe de } \\
\text { enfermagem }\end{array}$ & 19 & 20 & 2 & 38 \\
\hline
\end{tabular}

Finalizado esse percurso de busca, realizou-se a leitura dos resumos e os que apresentavam relevância para subsidiar a discussão do tema foram selecionados e lidos na íntegra.

A partir dessa leitura preliminar, foram selecionados 4 artigos que mantinham coerência com os descritores acima apresentados e com os objetivos do estudo. A partir dessa análise, foi extraída a bibliografia potencial, explicitada no Quadro 4 a seguir: 


\section{Quadro 4}

\begin{tabular}{|c|c|c|c|c|c|}
\hline Título & Autores & Objetivo & Revista & Ano & Principais conclusões \\
\hline $\begin{array}{l}\text { A importância } \\
\text { dos cuidados } \\
\text { paliativos } \\
\text { prestados pelo } \\
\text { enfermeiro à } \\
\text { criança com } \\
\text { câncer em } \\
\text { estágio terminal }\end{array}$ & $\begin{array}{l}\text { Carolina } \\
\text { Marinato } \\
\text { Bernardo; } \\
\text { Debora } \\
\text { Marinato } \\
\text { Bernardo; } \\
\text { Izabele } \\
\text { Alves } \\
\text { Costa, } \\
\text { Lidia } \\
\text { Rodrigues } \\
\text { Silva; } \\
\text { Williana } \\
\text { Graciele } \\
\text { Pires } \\
\text { Araujo; } \\
\text { Renê dos } \\
\text { Santos } \\
\text { Spezani. }\end{array}$ & $\begin{array}{l}\text { refletir sobre a } \\
\text { importância dos } \\
\text { cuidados paliativos } \\
\text { prestados pelo } \\
\text { enfermeiro à criança } \\
\text { com câncer em } \\
\text { estágio terminal. }\end{array}$ & $\begin{array}{l}\text { Revista } \\
\text { de } \\
\text { pesquisa } \\
\text { cuidado } \\
\text { é } \\
\text { fundame } \\
\text { ntal } \\
\text { online. }\end{array}$ & 2013 & $\begin{array}{l}\text { os resultados deste } \\
\text { estudo ratificam a } \\
\text { importância da atuação } \\
\text { do enfermeiro, onde a } \\
\text { proximidade de } \\
\text { vínculos permitirá uma } \\
\text { prática de enfermagem } \\
\text { mais efetiva e } \\
\text { consciente entre todos } \\
\text { os envolvidos. }\end{array}$ \\
\hline $\begin{array}{l}\text { Cuidado } \\
\text { paliativo ao } \\
\text { cliente } \\
\text { oncológico: } \\
\text { percepções do } \\
\text { acadêmico de } \\
\text { enfermagem }\end{array}$ & $\begin{array}{l}\text { Thamirez } \\
\text { A. Vieira; } \\
\text { Marcia } \\
\text { Oliveira; } \\
\text { Elizabeth } \\
\text { Rose Costa } \\
\text { Martins; } \\
\text { Cristiane } \\
\text { Maria } \\
\text { Amorim } \\
\text { Costa; } \\
\text { Rafaela } \\
\text { Nunes } \\
\text { Alves; } \\
\text { Cristiano } \\
\text { Bertolossi } \\
\text { Marta. }\end{array}$ & $\begin{array}{l}\text { Identificar o saber } \\
\text { dos acadêmicos de } \\
\text { enfermagem com } \\
\text { relação aos cuidados } \\
\text { paliativos e discutir o } \\
\text { diferencial deste } \\
\text { profissional para a } \\
\text { qualidade do cuidar } \\
\text { ao cliente oncológico } \\
\text { em estágio avançado }\end{array}$ & $\begin{array}{l}\text { Revista } \\
\text { online } \\
\text { de } \\
\text { pesquisa } \\
\text { cuidado } \\
\text { é } \\
\text { fundame } \\
\text { ntal. }\end{array}$ & 2017 & $\begin{array}{l}\text { Acreditamos que a boa } \\
\text { prática deve ser } \\
\text { resultado de muita } \\
\text { dedicação, de busca } \\
\text { por conhecimentos } \\
\text { científicos, e } \\
\text { principalmente, pelo } \\
\text { fortalecimento do ser } \\
\text { humano que existe em } \\
\text { cada profissional }\end{array}$ \\
\hline $\begin{array}{l}\text { Assistência de } \\
\text { enfermagem ao } \\
\text { paciente } \\
\text { oncológico } \\
\text { hospitalizado: } \\
\text { diagnósticos e } \\
\text { intervenções } \\
\text { relacionadas às } \\
\text { necessidades } \\
\text { psicossociais e } \\
\text { psicoespirituais }\end{array}$ & $\begin{array}{l}\text { Juliane } \\
\text { Portella } \\
\text { Ribeiro; } \\
\text { Letícia } \\
\text { Silveira } \\
\text { Cardoso; } \\
\text { Claúdia } \\
\text { Maria } \\
\text { Silva } \\
\text { Pereira; } \\
\text { Bárbara } \\
\text { Tarouco } \\
\text { Silva; } \\
\text { Betania } \\
\text { Kohler }\end{array}$ & $\begin{array}{l}\text { Identificar os } \\
\text { diagnósticos e } \\
\text { intervenções de } \\
\text { enfermagem acerca } \\
\text { das necessidades } \\
\text { psicossociais e } \\
\text { psicoespirituais de } \\
\text { pacientes } \\
\text { oncológicos. }\end{array}$ & $\begin{array}{l}\text { Revista } \\
\text { online } \\
\text { de } \\
\text { pesquisa } \\
\text { cuidado } \\
\text { é } \\
\text { fundame } \\
\text { ntal. }\end{array}$ & 2016 & $\begin{array}{l}\text { É imperativo } \\
\text { compreender o } \\
\text { impacto causado pelo } \\
\text { câncer, pois tal } \\
\text { entendimento } \\
\text { possibilita o } \\
\text { estabelecimento de } \\
\text { diagnósticos e de } \\
\text { intervenções de } \\
\text { enfermagem adequadas } \\
\text { ao momento vivido. }\end{array}$ \\
\hline
\end{tabular}




\begin{tabular}{|c|c|c|c|c|c|}
\hline & $\begin{array}{l}\text { Bubolz; } \\
\text { Caroline } \\
\text { Krüger } \\
\text { Castro. }\end{array}$ & & & & \\
\hline $\begin{array}{l}\text { Cuidados } \\
\text { paliativos à } \\
\text { criança com } \\
\text { câncer. }\end{array}$ & $\begin{array}{l}\text { Jael Rúbia } \\
\text { Figueiredo } \\
\text { de Sá } \\
\text { França; } \\
\text { Solange } \\
\text { Fátima } \\
\text { Geraldo da } \\
\text { Costa; } \\
\text { Maria } \\
\text { Miriam } \\
\text { Lima da } \\
\text { Nóbrega; } \\
\text { Maria } \\
\text { Emília } \\
\text { Limeira } \\
\text { Lopes. }\end{array}$ & $\begin{array}{l}\text { objetivou } \\
\text { compreender a } \\
\text { experiência } \\
\text { existencial de } \\
\text { enfermeiros, no } \\
\text { cuidar de crianças } \\
\text { com câncer sem } \\
\text { possibilidades } \\
\text { terapêuticas. }\end{array}$ & $\begin{array}{l}\text { Revista } \\
\text { de } \\
\text { enferma } \\
\text { gem } \\
\text { UERJ. }\end{array}$ & 2013 & $\begin{array}{l}\text { Os cuidados paliativos } \\
\text { são um instrumento } \\
\text { eficaz no cuidado com } \\
\text { a criança com câncer, } \\
\text { para promover uma } \\
\text { comunicação autêntica } \\
\text { e um vínculo entre ela } \\
\text { e o enfermeiro, que } \\
\text { pode desenvolver um } \\
\text { processo terapêutico } \\
\text { baseado em valores } \\
\text { humanísticos } \\
\text { universais, com } \\
\text { benefícios para ambos }\end{array}$ \\
\hline
\end{tabular}

Uma vez criadas às categorias de análise, partiu-se para a fase final de inferência e discussão dos dados obtidos, mediante o respaldo obtido através da articulação entre o conteúdo verificado nas produções científicas e a atitude crítico-reflexiva das pesquisadoras, através da qual desejamos identificar protagonização do enfermeiro na assistência ao paciente oncológico paliativo.

Diante do pouco números de estudos relacionados ao tema, e na escassez de artigos relacionados ao tema proposto, optou-se por recorrer ao google acadêmico para busca aleatória de artigos para utilização na discussão dos resultados.

\section{Resultados e Discussão}

\section{Categoria 1 - Assistência de enfermagem ao paciente sob cuidados paliativos}

A equipe de enfermagem é de suma importância ao paciente em cuidados paliativos e, também serve de apoio para a família, dando todo suporte necessário e segurança ao paciente em fase terminal, contribuindo para o conforto do paciente.

O enfermeiro está diretamente ligado a assistência do paciente em fase terminal, não só no cuidado direto como também como orientador ao paciente e a família, dando apoio necessário e favorecendo a interação e a participação da família com o paciente. Para isso deve ser devidamente qualificado para desempenhar tal função. Apesar dos cuidados 
paliativos não oferecerem cura, o papel do enfermeiro é oferecer conforto ao paciente e aliviar a dor (Bernardo et. al., 2013).

Desde os primórdios da enfermagem, o cuidado ao ser humano é o fundamento da profissão, desempenhando de funções direcionadas para a cura das doenças e à regeneração da saúde. A equipe de enfermagem participa diretamente da evolução da terapêutica e encontra-se presente ao termino da vida, cabendo-lhe assistir ao paciente sem possibilidades terapêuticas e familiares. Ao cuidar do paciente oncológico, os profissionais de enfermagem experimentam situações de sofrimento, angústia, medo, dor e de revolta vivenciadas pelo paciente e por seus familiares e, como seres humanos com emoções e sentimentos, em alguns momentos manifestam as mesmas reações (Almeida et.al., 2014).

Segundo Caropes, et al, (2016), os cuidados paliativos são um tipo especial de cuidado voltado para o conforto não só ao paciente, como também aos seus familiares na fase final da vida. Os cuidados paliativos estão voltados para prolongar a vida de maneira confortável e esta diretamente ligado à cuidado humanizado, uma vez que preta assistência ao paciente na pior fase da vida sem qualquer esperança de sobrevida, contudo oferecendo ao paciente controle da dor e dignidade na fase final da vida assim como convívio com seus familiares até os últimos momentos.

Para Brandão, et. al (2017), os cuidados paliativos devem iniciar desde o início do diagnóstico da doença, e se estender durante todo o acompanhamento e tratamento. Atua diretamente no acompanhamento dos pacientes que enfrentam doenças que comprometem a vida, contribuindo para melhora da qualidade de vida desse paciente com medidas de prevenção e alívio da dor. Com isso o diagnóstico precoce, torna-se de suma importância para a eficácia do cuidado paliativo. Esse cuidado tem se tornado cada vez mais importante devido à demanda cada vez maior de pacientes que não respondem ao tratamento de forma satisfatória. É necessária a atuação de toda a equipe de saúde, pois atende ao paciente biopsicossocial e não somente no tratamento da doença. Desta forma, a assistência do enfermeiro deve ser voltada não apenas para o paciente e sua patologia como também, aos seus familiares, incentivando e favorecendo a proximidade e vínculo entre a família e o paciente, fortalecendo a interação e interferindo na qualidade dos cuidados paliativos prestados ao paciente oncológico.

Segundo Andrade \& Torres (2015) a dor é um sinal subjetivo, e pode estar relacionada ao emocional e não a doença propriamente dita. A dor oncológica não é diferente e pode estar relacionada ou não à neoplasia, pois se deve levar em consideração o estado emocional do paciente, por isso a importância de se observar o paciente de forma holística e estar sempre 
atento às suas necessidades. A dor é considerada o quinto sinal vital e como tal deve ser verificada junto com os outros sinais vitais.

A base da assistência da enfermagem é o cuidado, e o enfermeiro deve possuir conhecimentos específicos para cuidar do paciente oncológico paliativo, pois engloba o controle da dor ao administrar analgésico, assim como a comunicação e aceitação do paciente no processo de aceitação da doença terminal (Freitas \& Pereira, 2013).

Segundo Silva \&Ponte (2015) o conforto é resultado do cuidado de enfermagem, e possui significados diferentes, conforme as realidades vivenciadas, o conforto é um estado de equilíbrio pessoal e ambiental. Apresenta-se como uma necessidade básica própria do ser humano, o quer esteja ou não vivenciando um processo de adoecimento. Assim, o fenômeno conforto vem, ao longo dos tempos, sendo estudado por enfermeiros. Florence Nightingale, compreendida como primeira teórica da enfermagem, já abordava o conforto como meta do cuidado de enfermagem.

O conforto é contemplado como uma experiência imediata, fortalecida pela sensação de alívio, tranquilidade e transcendência. Trata-se, portanto, da satisfação das necessidades humanas básicas, resultante do cuidado de enfermagem, proporcionada por meio de intervenções denominadas medidas de conforto, é também um fenômeno importante nas práticas do cuidado e nos diversos contextos de cuidar da enfermagem e que precisa de constante aprofundamento (Silva \& Ponte, 2015).

Considerando os problemas que surgem com os cuidados no fim da vida, expõe-se a necessidade de aprofundar o debate sobre a proximidade da morte e a terminalidade humana (Paiva et.al., 2014).

Estudos comprovam que o paciente terminal demanda mais atenção da equipe de enfermagem a equipe de enfermagem, do que de qualquer outro profissional da área da saúde. A enfermagem deve promover conforto, ajudar a família e o paciente a lidar com a proximidade da morte, ouvir as queixar do paciente e estimular o autocuidado. A enfermagem deve promover o alívio da dor e de qualquer outro sintoma (Vieira et. al., 2017).

O paciente em fase terminal deve ser assistido de forma integral, oferecendo alivio de qualquer desconforto que o paciente possa sentir. A família também desempenha papel de suma importância no conforto do paciente, pois também interferem no bem estar do paciente, tornando - se importante também o cuidado com a família e a enfermagem deve estar sempre atenta às necessidades do paciente e aos reflexos que a família pode ter na assistência ao paciente (Vieira et. al., 2017). 
Paciente sob cuidados paliativos, deve ser visto de maneira holística em todas as suas necessidades físicas, emocional, social e espiritual. Deve-se ainda compreender que a dor é um sinal subjetivo devendo sempre levar em consideração todas as queixas do paciente, por isso a importância da assistência de enfermagem ao paciente terminal (França et. al., 2013).

A assistência e enfermagem ao paciente terminal, está relacionada a qualidade de vida de amenizar o sofrimento do paciente no fim da vida, ainda que a não seja possível alcançar a cura. O longo período de tratamento do paciente oncológico leva a uma convivência mais próxima com os profissionais de enfermagem isso, favorece a interação com o paciente e a família influenciando na assistência prestada ao paciente, oferecendo também suporte emocional ao paciente e à família e essa relação via além de procedimentos técnicos, pois se refere a oferecer apoio e atenção ao paciente a família. No que se refere a cuidado paliativo, a premissa do cuidado é o conforto, ainda que a cura não seja possível, esse paciente deve ser assistido em todas as suas necessidades, assim como controle da dor, oferecendo qualidade de vida para o paciente durante o tempo que for necessário (Daronco et. al., 2014).

Daronco et. al (2014), também salienta a importância da família do cuidado e na interação com o paciente terminal, uma vez que um bom relacionamento com a família interfere diretamente no bem estar do paciente, além de poder enfrentar esse momento de dificuldade com seus familiares.

Torna-se importante salientar que a enfermagem também é afetada emocionalmente com a situação do paciente terminal, pois oferece não só assistência profissional como também apoio emocional, estreitando os laços com o paciente. Sendo assim, a enfermagem se baseia na arte do cuidar (Hermes \& Lamarca, 2013).

Desta- se ainda, a importância de profissionais qualificados na assistência ao paciente terminal oncológico e comprometidos a especificidade desse tipo de paciente, pois requer uma assistência qualificada e individualizada (Cardoso, et al, 2013).

Diante do exposto, a atuação da enfermagem é de suma importância na assistência ao paciente terminal oncológico, oferecendo controle da dor e conforto, porém transcende o apoio profissional e passa a oferecer apoio emocional e cuidado humanizado ao paciente em situação de impossibilidade de cura. 


\section{Categoria 2 - Aplicação da Sistematização da Assistência de Enfermagem ao paciente terminal oncológico}

A Sistematização da Assistência de Enfermagem (SAE) é uma forma de organizar o trabalho e inclui o Processo de Enfermagem (PE), que orienta a assistência da enfermagem em cinco etapas relacionadas: coleta de dados, diagnostico de enfermagem, planejamento, implementação e avaliação de enfermagem. Sua implementação garante qualidade da assistência de enfermagem e norteia suas ações, proporcionando assistência de qualidade e individualizada (Silva, Garanhanes \& Peres, 2015).

Segundo o COFEN (2009), na resolução 358/2009 determina que, é exclusivo do enfermeiro o diagnóstico de enfermagem e a liderança e avaliação do Processo de Enfermagem.

Numer, Both \& Rosanelli (2018), diz que com o crescimento dos casos de câncer no Brasil, se faz necessário a implementação de uma assistência de qualidade e individualizada, oferecendo humanização e sistematização, evitando agravos à saúde e promovendo melhor qualidade de vida, e a SAE é a ferramenta que irá auxiliar nesse processo.

É um método cientifico que tem como finalidade assistir ao paciente de maneira holística, oferecendo assistência individualizada e de qualidade. A equipe de enfermagem, deve estar preparada para implementar a SAE, favorecendo o cuidado holístico, promovendo a recuperação e observando as necessidades do paciente (Marineli; Silva \& Silva, 2015).

No paciente terminal oncológico a SAE, influencia diretamente na avaliação e controle da dor, com planejamento e atendendo às necessidades do paciente oferecendo uma assistência de qualidade (Andrade \& Torres, 2015).

A utilização do diagnóstico de enfermagem, traz benefícios tanto para o paciente quanto para o desempenho das atividades de enfermagem em si, pois orientam através do processo de enfermagem, quanto às necessidades individuais de cada paciente. E tem suma importância ao paciente oncológico terminal, pois possibilita assisti-lo em todas as suas necessidades biopsicossociais (Ribeiro, 2016).

Dentre os diagnósticos de enfermagem mais utilizados voltados para o paciente oncológicos terminais estão: ansiedade e medo, risco da dignidade humana comprometida, distúrbio de identidade pessoal, sentimento de impotência, risco de solidão, baixa autoestima situacional, distúrbio de imagem corporal, processos familiares interrompidos, disposição para o processo familiar melhorado, processo familiar disfuncional, interação social prejudicada, síndrome de estresse por mudança, medo, ansiedade relacionado à morte, 
tristeza, negação ineficaz, sobrecarga de estresse, pesar, isolamento social e conforto prejudicado (Ribeiro, 2016).

O diagnóstico e o processo e enfermagem são instrumentos importantes na assistência e enfermagem e no desempenho as atividades o enfermeiro, pois serve e base para as intervenções e enfermagem, favorecendo o desempenho as atividades, a tomada e decisão necessários para a assistência ao paciente, os resultados esperados, oferecendo os cuidados de acordo com as necessidades o paciente (Leite et. al., 2013).

Leite (2013), estaca que ainda existem dificuldades na implementação da SAE, pois á relatos de enfermeiros que não sabem utilizar a SAE de maneira correta e, apesar de reconhecerem sua importância na assistência e enfermagem, existem diversos fatores e dificultam sua correta aplicação.

Segundo Soares (2015), com o passar dos anos e a evolução da tecnologia, a SAE e o processo e enfermagem tem sido cada vez mais necessários na assistência de enfermagem, corroborando para a importância da aplicação da SAE. Apesar e ainda ter dificuldades na sua implementação, é notório que por meio da SAE é possível, direcionar, planejar e organizar a assistência à enfermagem.

Também é função o enfermeiro, orientar e envolver toda equipe de enfermagem sobre a importância da aplicação da SAE, pois apesar das dificuldades sua correta utilização favorece a equipe e o paciente, contribuindo para uma assistência e qualidade, atendendo as necessidades do paciente e da família (Soares, 2015).

Um dos problemas na implementação da SAE é a falta de informação nos registros do enfermeiro, dificultando sua implementação correta, levando a uma divergência entre o que é feito na assistência e o que está no registro do enfermeiro. Diante disso, a implementação da SAE torna-se um desafio para a assistência e enfermagem, pois exige do enfermeiro constante empenho na execução desse instrumento, mantendo todos envolvidos na melhor assistência para o paciente. Existem ainda, dificuldades relacionadas as instituições de saúde, principalmente públicas, pois existem fatores que dificultam sua implementação devido à problemas administrativos e assistenciais, dificultando a qualidade da assistência oferecida ao paciente (Soares, 2015).

Diante disso fica clara a importância da atuação da enfermagem na aplicação do diagnóstico de enfermagem, e não se aplica apenas à dor e questões fisiológicas, como também as questões psicológicas e sociais e espirituais, corroborando para importância da SAE e do processo de enfermagem no cuidado ao paciente oncológico. 


\section{Considerações Finais}

Diante o exposto, fica claro que a enfermagem é de suma importância na assistência ao paciente terminal oncológico, pois é a enfermagem que está presente em todos os momentos e oferece suporte não só à doença, como emocional ao paciente e a família, pois em momentos de enfrentamento da morte a família deve estar próxima em todos os momentos, dando apoio ao paciente.

A SAE é o instrumento utilizado para sistematizar a assistência de enfermagem, e o enfermeiro é o principal responsável por sua aplicabilidade e como já exposto, tornar-se de suma importância na assistência ao paciente, porém ainda existem dificuldades na sua utilização que devem ser eliminadas com para que seja possível uma assistência completa e de qualidade.

É importante ressaltar o conhecimento do enfermeiro sobre a SAE, pois há relatos de enfermeiros que não dominam com segurança essa ferramenta, demonstrando a importância da constante busca pelo aprimoramento profissional, influencia diretamente na qualidade da assistência prestada ao paciente.

É importante salientar a escassez de estudos voltados para o tema, corroborando para a importância desta pesquisa e para o aprofundamento de mais estudos relacionados a SAE e aos cuidados paliativos na assistência de enfermagem.

Por fim, espera com este estudo salientar a importância da assistência do enfermeiro e da equipe de enfermagem ao paciente terminal oncológico, e como a SAE influencia positivamente na assistência de enfermagem, pois está diretamente ligada a qualidade da assistência em todas as áreas da saúde e principalmente quando se trata de cuidados paliativos, devido a especificidade desse tipo de paciente, onde a enfermagem atua no controle da dor e de qualquer outra queixa do paciente dando suporte emocional ao paciente e a família.

\section{Referências}

Andrade DS; Torres VPS. (2015) Perspectivas do enfermeiro frente aos cuidados para alivio da dor no paciente terminal oncológico. Persp. Online: biol. \& saúde, Campos dos Goytacazes; 19(5): 63-77. 
Bernardo CM; Bernardo DM; Costa IA; et al. (2014) A importância dos cuidados paliativos prestados pelo enfermeiro à criança com câncer em estagio terminal. J. res.: fundam. care. Online. 6(3):1221-1230

Brandão MCP; Anjos KF; Sampaio KCP; et al. (2017) Cuidados paliativos do enfermeiro ao paciente oncológico. Rev. Bras. de Saúde Funcional-REBRASF. 2017;1.2

Braz IFL; Gomes RAD; Azevedo MS; et al. (2018). Análise da percepção do câncer por idosos. Einstein. São Paulo; 16(2).

Cardoso DH; Muniz RM; Schwartz E; Arriera ICO. (2013) Cuidados paliativos na assistência hospitalar: a vivência de uma equipe multiprofissional. Texto contexto - enferm. Florianópolis; 22(4).

Coropes VBAS; Valente GSC; Oliveira ACF; et al. (2016) A assistência dos enfermeiros aos pacientes com câncer em fase terminal: revisão integrativa. Ver enferm. UFPE online, Recife, 10 (supl.6): 4920-6.

Daronco VF; Rosanelli CLSP; Loro MM; Kolankiewicz ACB. (2014). Cuidados paliativos a pacientes oncológico: percepções de uma equipe de enfermagem. Cienc. Cuid. Saúde.; 13 (4): $657-664$

Fernandes MA; Evangelista CB; Platel ICS; et al. (2015). Percepção dos enfermeiros sobre o signifado dos cuidados paliativos em pacientes com câncer terminal. Ciênc. saúde coletiva [online]; 18(9): 2589-2596.

Fernandes MC; Silva FMP; Costa SP, et al.(2016). Facilidades e dificuldades das enfermeiras gerentes na implementação da gerência do cuidado no ambiente hospitalar. Rev. Fund. Care Online. 8 (4): 5039-5044.

França JRFS; Costa SFG; Nóbrega MML; et al. (2013). Cuidados paliativos à crianças com câncer. Rev. enferm. UERJ, Rio de Janeiro; 21(esp.2): 779-84. 
Freitas NO; Pereira MVG. (2013). Percepção dos enfermeiros sobre cuidados paliativos e o manejo da dor na UTI. O mundo da saúde, São Paulo; 37 (4): 450-457.

Hermes HR; Lamarca ICA; (2013). Cuidados paliativos: uma abordagem a partir das categorias profissionais de saúde. Ciênc. saúde coletiva vol.18 no.9 Rio de Janeiro.

Leite FMC; Ferreira FM; Cruz MAS; et al. (2013). Diagnósticos de enfermagem relacionados aos efeitos adversos da radioterapia. Rev. Min. Enferm. out./dez.; 17(4): 940-945.

Marinelli NP; Silva ARA; Silva DNO. (2015). Sistematização da assistência de enfermagem: desafios para implantação. Rev. Enfern. contemporânea., jul./dez.: 4 (2): 254-263.

BRASIL, (2012). Ministério da Saúde. Instituto Nacional do Câncer (INCA). Ações de enfermagem para o controle do câncer: uma proposta de integração ensino-serviço. 3.ed.. Rio de Janeiro, 2012.

Monteiro, TA. et al. A atuação do enfermeiro junto a criança com câncer: cuidados paliativos. Rev enferm UERJ, Rio de Janeiro; 22(6):778-783

Guerrero, GP.; Zago, MMF; Sawada, NO; Pinto, MH. (2011). Relação entre espiritualidade e câncer: perspectiva do paciente. Rev. Bras. Enferm. 2011; 64(1): 53 - 59.

Gil AC; (2008). Métodos e técnicas de pesquisa social. $6^{\circ}$ ed. - São Paulo: Atlas.

Minayo, MCS. (2008). O Desafio do conhecimento: pesquisa qualitativa em saúde. 11. ed. São Paulo. Ed Hucitec.

Lakatos, EM; Marconi, NA. (2010). Fundamentos de Metodologia Cientifica. 7. ed. São Paulo. Ed. Atlas, 2010.

Ministério da Saúde [BR]. Saúde de A a Z. Câncer: sintomas, causas, tipos e tratamentos.

Ministério da Saúde [BR]. Instituto Nacional de Câncer - INCA. Câncer, causa e prevenção, conviver com câncer. 
Numer C; Both CT; Rosanelli CSP. (2018). Sistematização da assistência de enfermagem a um paciente com câncer colorretal: contribuição para enfermagem. Rev. Espaço ciência \& saúde, v.6, n.1, p.86-96

Ribeiro JP; Cardoso LS; Pereira CMS; et al. (2015) Assistência de enfermagem ao paciente oncológico hospitalizado: diagnósticos e intervenções relacionadas às necessidades psicossociais e psicoespirituais. Rev. Fund. Care Online. out./nov./dez.; 8(4):5136-5142.

Salimena AMO; Teixeira SR; Amorim TV; et al. (2013) Estratégias de enfrentamento usadas por enfermeiros ao cuidar de pacientes oncológicos. Rev. Enferm UFSM, jan./abr.; 3(1): 8-16.

Silva JP; Garanhani ML; Peres AM. (2017). Sistematização da assistência de enfermagem na graduação: um olhar sob o Pensamento Complexo. Rev. Latino-Am. Enfermagem jan./fev; 23(1): 59-66.

Vieira TA; Oliveira M; Martins ERC; et al. (2017) Cuidado paliativo ao cliente oncológico: percepções do acadêmico de enfermagem. Rev. Fund. Care Online. jan./mar.; 9(1): 175-180.

\section{Porcentagem de contribuição de cada autor no manuscrito}

Wanderson Alves Ribeiro - 30\%

Bruna dos Santos Bulhões Felipe - $40 \%$

Raísa Vitória Guedes de Oliveira - 40\% 